\title{
The Outstanding 2004/05 Drought in the Iberian Peninsula: Associated Atmospheric Circulation
}

\author{
Ricardo García-Herrera, ${ }^{*}$ Daniel Paredes, ${ }^{+}$Ricardo M. Trigo, ${ }^{\#}$ Isabel Franco Trigo, $@$ \\ Emiliano Hernández,* David Barriopedro,* and Manuel A. Mendes \& \\ * Departamento de Física de la Tierra II, Facultad de Físicas, Universidad Complutense, Madrid, Spain \\ * Departamento de Física de la Tierra II, Facultad de Físicas, Universidad Complutense, Madrid, Spain, and University of Lisbon, \\ CGUL, IDL, Lisbon, Portugal \\ \# University of Lisbon, CGUL, IDL, and Departamento de Engenharias, Universidade Lusófona, Lisbon, Portugal \\ @ Instituto de Meteorologia, and University of Lisbon, CGUL, IDL, Lisbon, Portugal \\ \& Instituto de Meteorologia, Lisbon, Portugal
}

(Manuscript received 29 March 2006, in final form 11 September 2006)

\begin{abstract}
The 2004/05 hydrological year (October 2004 to September 2005) was characterized by intense dry conditions affecting most of western Europe $\left(35^{\circ}-55^{\circ} \mathrm{N}\right.$ and $\left.10^{\circ} \mathrm{W}-10^{\circ} \mathrm{E}\right)$. In Iberia the drought affected every month of this period, with the southern half of Iberia receiving roughly $40 \%$ of the usual precipitation by June 2005. Moreover, this episode stands as the driest event in the last $140 \mathrm{yr}$, producing major socioeconomic impacts particularly due to the large decrease in hydroelectricity and agricultural production in both Iberian countries (Portugal and Spain).

To assess the atmospheric submonthly circulation associated with this drought an Eulerian [weather types (WTs)] and a Lagrangean (objective storm tracks) analysis were combined. There was a dramatic drop in "wet" WT frequency during winter, with less than $50 \%$ of the normal value, and a corresponding increase of "dry" WTs. The storm-track analysis reveals an impressive northward displacement of cyclone trajectories in the North Atlantic sector in winter months, resulting in an almost complete absence of cyclones crossing Iberia and western Europe.

At the monthly scale, the intense drought in Iberia was due to a combination of different physical mechanisms. First, the scarce precipitation observed between November 2004 and January 2005 was associated with positive North Atlantic Oscillation (NAO) indexes for these months. In February, the East Atlantic (EA) pattern seems to be the main driver. In March neither the negative NAO (-1.8) nor the positive EA (1.1) are capable of explaining the large negative precipitation anomalies. However, it is shown that during March 2005, an intense and anomalous blocking was displaced southward of its usual location, inhibiting the occurrence of precipitation over Iberia and leading to a negative NAO index anomalously associated with low precipitation records.
\end{abstract}

\section{Introduction}

The recent 2004/05 hydrological year was characterized by one of the worst droughts ever recorded in the Iberian Peninsula, particularly in the central and southern sectors. Using data from the Global Precipitation Climatology Center (GPCC) we computed the spatially averaged precipitation over Iberia, between October 2004 and June 2005, which corresponds to roughly 45\% less than the 1961-90 climatological average (Fig. 1).

Corresponding author address: Ricardo García-Herrera, Dto. Física de la Tierra II, Facultad de Físicas, Universidad Complutense, Av. Complutense s/n, C.P. 28040 Madrid, Spain.

E-mail: rgarciah@fis.ucm.es
However, if we look at the spatial variability of this decrease, it is immediately striking that a significant percentage of the southern half of the Iberian Peninsula received $60 \%$ less than the average precipitation (Fig. 1).

The occurrence of intense droughts in Iberia is a usual feature of its precipitation regime, characterized by a strong interannual and decadal variability (Esteban-Parra et al. 1998). Nevertheless, the decades of the 40 s and the early 50s along with the 80s and 90s are described as particularly dry throughout the whole Iberian territory (Vicente-Serrano 2006a,b). These extremely dry periods in Iberia coincide with a large drought incidence over much of the European continent (Briffa et al. 1994; Dai et al. 1998, 2004; Lloyd-

DOI: $10.1175 / J H M 578.1$

(C) 2007 American Meteorological Society 


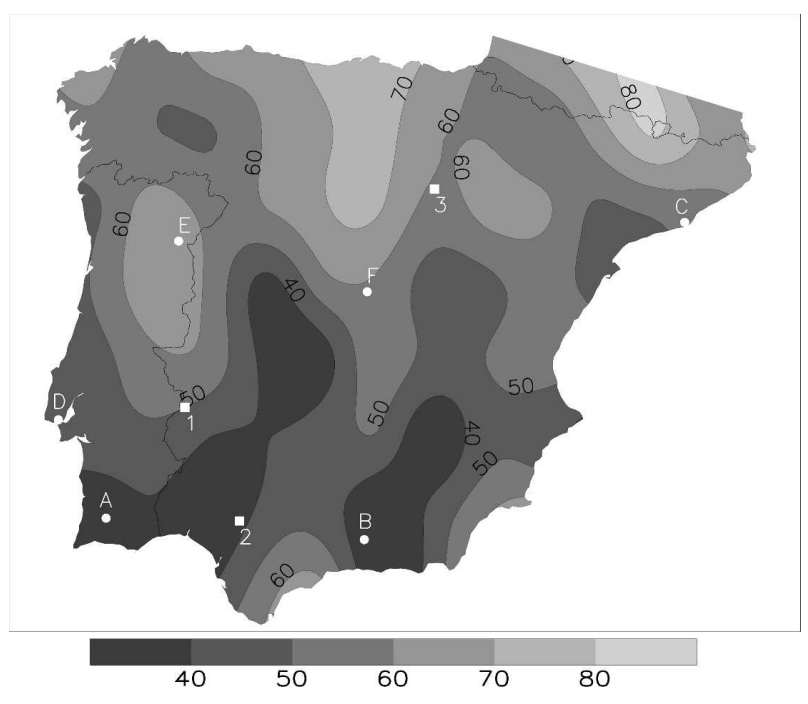

FIG. 1. October 2004-June 2005 accumulated precipitation percentage of the normal 1961-90 period for the Iberian Peninsula, using the monthly GPCC precipitation dataset: (a) the Reliquias station, (b) Granada, (c) Barcelona, (d) Lisbon, (e) Pocinho, and (f) Madrid.

Hughes and Saunders 2002a) and, in particular, with several intense drought episodes over the northern Mediterranean area (Maheras et al. 1999; Delitala et al. 2000).

Anyway, the low precipitation amount and wide spatial impact of the 2004/05 drought have prompted this event to become one of the most distressing episodes suffered in Iberia. According to the Spanish and Portuguese authorities, several stations with long-term precipitation series across central Spain and Portugal (Fig. 1) recorded the worst drought episode since the late nineteenth century (e.g., Madrid since 1859; Soria since 1865; Lisbon since 1865). Over southern Iberia (e.g., Sevilla since 1876; Badajoz since 1866; Granada since $1865)$ this event corresponds to the second most intense drought in the last $130 \mathrm{yr}$ (MMA 2006).

This fact has produced large political and social unrest, as water levels in Spanish and Portuguese dams were reduced to circa $55 \%$ of their total by June 2005 (MMA 2006; INAG 2006). Naturally, river flow values dropped considerably throughout Iberia, which even reached record values, for example, the Douro River in January (Fig. 2). These very low river flow values between December 2004 and June 2005 had a direct negative impact in terms of hydroelectric power production. To overcome this shortage in hydroelectricity production, both countries had to rely on massive imports of oil, natural gas, and coal to produce electricity from thermoelectric power plants.

Iberian precipitation is also characterized by large

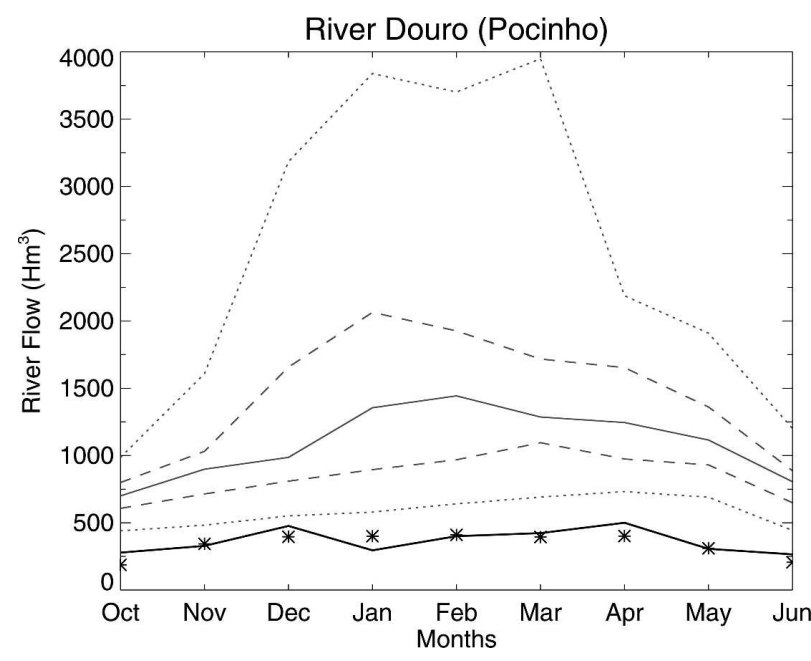

FIG. 2. Monthly river flow at the Portuguese Pocinho station (Fig. 1e) located in the Douro River near the Spanish border. Solid black line depicts the monthly record for the October 2004June 2005 period. Light gray lines indicate several percentile values of the 1961-90 period: 50th (solid), 30th and 70th (dashed), and 10th and 90th percentiles (dotted). Asterisks show the minimum value recorded.

spatial variability (Esteban-Parra et al. 1998; Trigo and DaCamara 2000). This spatial complexity has also been displayed in several drought analyses performed for the entire peninsula, which have identified several distinct drought patterns throughout Iberia (Martín-Vide and Gómez 1999; Lana et al. 2001; Vicente-Serrano 2006a,b). These regions are consistent with the spatial precipitation patterns accounting for the largest part of precipitation variability over Iberia at the annual, seasonal, and monthly scales (RodriguezPuebla et al. 1998; Esteban-Parra et al. 1998; Serrano et al. 1999). As a consequence, even the most widespread drought episodes did not affect the entire territory of Iberia. Nevertheless, it is frequent that roughly $20 \%$ of the Iberian Peninsula territory is affected during a drought event, reaching more than $50 \%$ of the territory during the most intense episodes (Vicente-Serrano 2006a,b).

The largest concentration of rainfall in the Iberian Peninsula is recorded between October and March (Esteban-Parra et al. 1998; Trigo and DaCamara 2000; Trigo et al. 2004b; Paredes et al. 2006). Therefore, all major droughts in this region are characterized by lack of rainfall during several months of the winter half of the year (Trigo and DaCamara 2000). While the average precipitation in transition months (e.g., April, May, and September) has a relatively minor impact on annual totals, summer precipitation can be regarded as irrelevant. In fact, for the central and southern regions of Iberia, the average for the short hydrological year 
(between October of year $n-1$ and June of year $n$ ) represents $90 \%$ of the total hydrological year precipitation (not shown).

During the winter season, precipitation in Iberia is mainly related to transient low pressure systems with Atlantic origin, as shown by studies relating precipitation and circulation patterns at the daily scale by means of weather-type approaches (Trigo and DaCamara 2000; Goodess and Jones 2002; Paredes et al. 2006). The North Atlantic Oscillation pattern (NAO) controls, to a large extent, the preferred location of storm-track paths over the North Atlantic region (Trigo 2006; R. M. Trigo et al. 2002). Thus, it exerts strong control on precipitation variability over the Iberian Peninsula (Rodriguez-Puebla et al. 1998; Trigo et al. 2004b; Goodess and Jones 2002) and over parts of the European continent, showing the relevance of the NAO mode to the winter surface climate (R. M. Trigo et al. 2002).

However, other large-scale modes of atmospheric circulation, namely, the Eastern Atlantic (EA) and the Scandinavian (SCAN) patterns are also relevant to precipitation over Europe (Qian et al. 2000) as well as for Iberia (Rodriguez-Puebla et al. 1998; Sáenz et al. 2001). In a wider frame, El Niño-Southern Oscillation (ENSO) has also been proved to have a certain influence in the wet season of Iberian and European precipitation (Rodó et al. 1997; Mariotti et al. 2002; Lloyd-Hughes and Saunders 2002b; Vicente-Serrano 2005), which is probably linked to a NAO-like anomaly pressure pattern (Pozo-Vázquez et al. 2001, 2005).

The main objectives of this paper are as follows:

1) To characterize the temporal and spatial extent of the 2004/05 drought episode in Iberia using both daily and monthly datasets; the event is put into a broader temporal context by comparing its rank with other major droughts that took place in recent decades.

2) To analyze different physical mechanisms responsible for the decrease of precipitation between October 2004 and June 2005, with a particular emphasis on the role played by the anomalous paths of low pressure systems affecting this region, with respect to climatological averages. This will be achieved by means of an Eulerian (weather types) and a Lagrangean (objective storm tracks) analysis of sea level pressure (SLP) and 1000-hPa geopotential height fields, respectively.

3) Finally, we describe the role played by large-scale circulation modes, namely, the NAO, EA, and blocking episodes.

\section{Data and methodology}

\section{a. Precipitation datasets}

To analyze the precipitation over the Iberian Peninsula two different daily and monthly precipitation datasets were examined. The analysis of annual precipitation has been carried out for the standard definition of hydrological year currently used by water resources officials for Portugal and Spain, that is, the period spanning from October of year $n-1$ to September of year $n$ :

1) Daily precipitation data series between 1941 and 2005 were obtained from the Spanish National Meteorological Institute (INM; two stations, Granada and Barcelona), the Portuguese National Institute for Water Resources (INAG; one station, Reliquias), and the Geophysical Institute of Portugal (one station, Lisbon). These four stations presented less than $0.5 \%$ missing data and no infilling method was applied. Also, the long-term (1865-2005) monthly precipitation series for the station of Lisbon was analyzed (Geophysical Institute of Portugal).

2) The monthly precipitation dataset at $1.0^{\circ} \times 1.0^{\circ}$ resolution, provided by the GPCC (Rudolf and Schneider 2005), was used to visualize the spatial extent of the 2004/05 drought on a yearly (Fig. 1) and monthly basis. It covers the period from 1986 to 2005, although the 1961-90 normals are also available. This dataset, freely available at the GPCC site (http://gpcc.dwd.de), has already been used to analyze extreme dry precipitation episodes over Europe (Rudolf and Meyer-Christoffer 2005).

\section{b. Atmospheric circulation variables and temperature datasets}

The analysis of the atmospheric circulation at the monthly and synoptic scales over the North Atlantic and European sectors (hereafter NAE; $25^{\circ}-70^{\circ} \mathrm{N}$ latitude, $25^{\circ} \mathrm{W}-30^{\circ} \mathrm{E}$ longitude) relies on the European Centre for Medium-Range Weather Forecasts (ECMWF) reanalysis, available between 1957 and 2002 [40-yr ECMWF Re-Analysis (ERA-40)], and operational analysis from 2003 to 2005 (Uppala et al. 2005). Geopotential height at 1000 and $500 \mathrm{hPa}$, temperature at $850 \mathrm{hPa}$, and SLP fields have been interpolated to a $2.5^{\circ} \times 2.5^{\circ}$ regular grid (and to the reanalysis full spatial resolution $1.125^{\circ} \times 1.125^{\circ}$ grid for storm-tracking purposes) for the NAE sector. All monthly anomaly fields computed in this work were obtained after removing the corresponding climatological normals for the 196190 period. The North Atlantic teleconnection indexes 
(NAO and EA) and the ENSO index maintained by the Climate Prediction Center (CPC) were also analyzed.

\section{c. Methodologies}

The atmospheric synoptic features of the 2004/05 drought are characterized through the analysis of three additional databases of storm tracks, circulation weather types, and blocking events previously developed by the authors:

1) The daily weather-types scheme (WTs) allows the classification of daily surface flow over the Iberian Peninsula based on SLP daily charts (0000 UTC) obtained from $2.5^{\circ}$ latitude $\times 2.5^{\circ}$ longitude ECMWF reanalyses. The WT dataset was derived for the 1957-2005 period, using an algorithm previously developed by Trigo and DaCamara (2000). Ten distinct WTs are considered, including eight directional types dominated by strong nonrotational flow (within $45^{\circ}$ sectors) and two other WTs dominated by high absolute values of vorticity (cyclonic and anticyclonic types) (Trigo and DaCamara 2000; Paredes et al. 2006).

Anomaly SLP fields for the cyclonic (C), westerly flow (W), and anticyclonic (A) WTs for winter [December-February (DJF)] can be observed in Fig. 3; these were obtained after removing the winter climatology. The $\mathrm{C}$ and $\mathrm{W} \mathrm{WTs}$ contribute the highest fraction of winter (DJF) precipitation, while the A type is the most frequent and presents a low contribution to winter precipitation (Trigo and DaCamara 2000; Paredes et al. 2006). Spatial patterns obtained for corresponding WTs for the fall and spring seasons do not change significantly, although the magnitude of positive and negative anomalies is usually smaller. This classification has previously been applied for different studies on the Iberian precipitation regime (Trigo and DaCamara 2000; Goodess and Jones 2002; Paredes et al. 2006).

2) The detection and tracking of North Atlantic cyclones is based on an algorithm first developed for the Mediterranean region by Trigo et al. (1999, 2002) and recently adapted for the entire North Atlantic area (Trigo et al. 2004a; Trigo 2006). This scheme is performed using 6-hourly geopotential heights at $1000 \mathrm{hPa}$, available from ECMWF analysis, on a $1.125^{\circ} \times 1.125^{\circ}$ grid for the period between October 2004 and March 2005.

Cyclones are identified as minima in geopotential height fields at $1000 \mathrm{hPa}$, fulfilling a set of conditions regarding the central pressure and the geopotential gradient. The tracking is based on a nearest neighbor search in consecutive charts, assuming that the
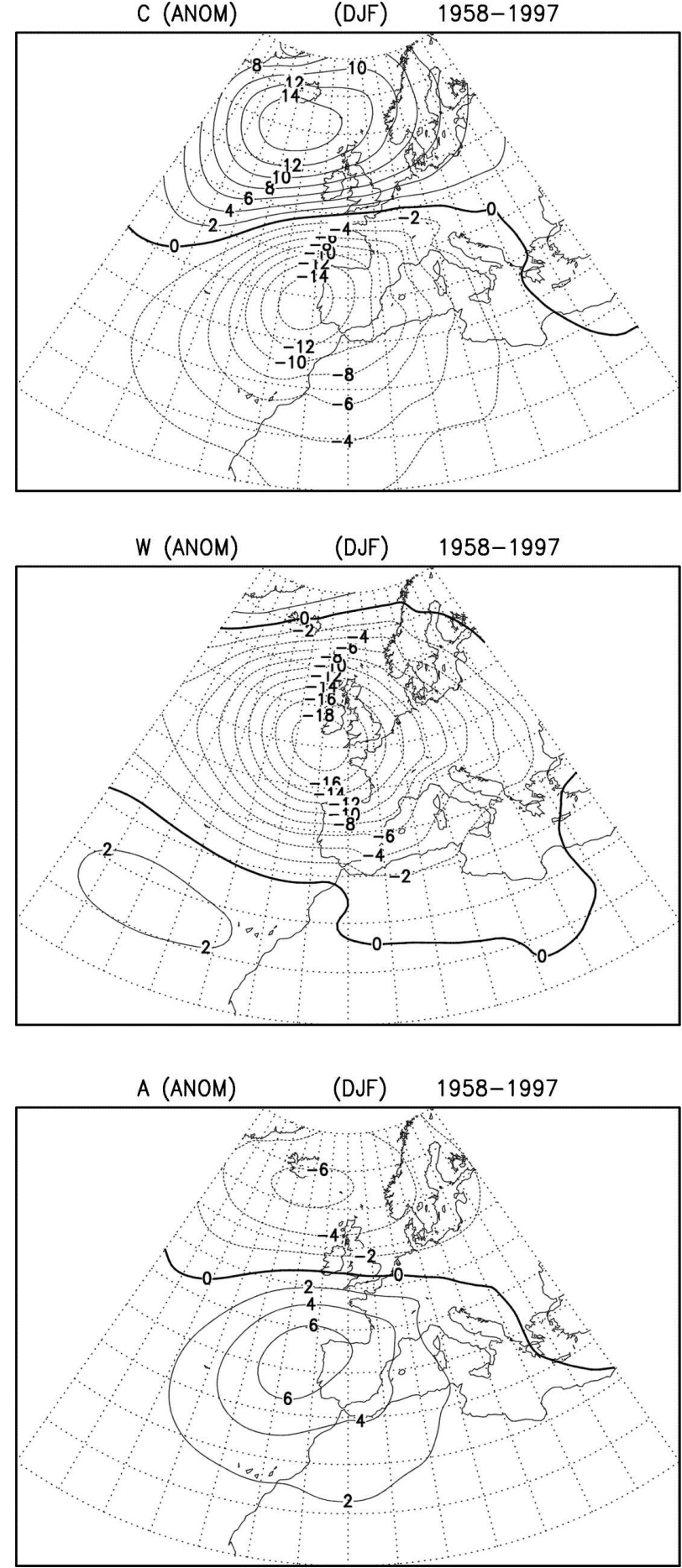

FIG. 3. Composite maps of anomaly SLP fields for the corresponding weather types: (top) $\mathrm{C}$, (middle) W, and (bottom) A for winter (DJF) during the period 1958-97. Dashed (solid) lines display negative (positive) anomalies. 
speed of individual storms is less than $50 \mathrm{~km} \mathrm{~h}^{-1}$ in the westward direction and $110 \mathrm{~km} \mathrm{~h}^{-1}$ in any other. Further details on the cyclone detecting and tracking methodology may be found in Trigo (2006). For the purpose of this study, only cyclones lasting a minimum of $48 \mathrm{~h}$ and presenting minimum pressure values below $1010 \mathrm{hPa}$ throughout their life cycle were considered.

3) The blocking detection methodology developed by Barriopedro et al. (2006) is applied to the Northern Hemisphere during the period 1958-2005. This technique is performed by using geopotential height reanalysis data at $500 \mathrm{hPa}$ from the ECMWF database. The application of the blocking algorithm allows the detection of those blocked longitudes for each day from a set of conditions imposed to the averaged zonal flow between $40^{\circ}$ and $60^{\circ} \mathrm{N}$. A blocking anticyclone is then identified when five or more adjacent longitudes are blocked for at least 5 days. The tracking procedure is then performed by comparing the overlapping areas in consecutive daily charts and computing the main parameters associated with blocking episodes, namely, duration, location of the blocking center, and extension in longitude. Further information may be found in Barriopedro et al. (2006).

\section{The major $2004 / 05$ drought}

\section{a. Iberia}

To show the magnitude of the 2004/05 drought, we have used the longest daily data series available (October 1941-June 2005) for three stations across the southern and eastern parts of the peninsula (Fig. 1, Reliquias, Portugal; Granada and Barcelona, Spain). This event broke existing records by the beginning of the summer season (Fig. 4a, Reliquias, and Fig. 4c, Barcelona). The shortage of precipitation during the winter season is clearly noticeable at the daily scale; unlike previous severe drought episodes that typically recorded low precipitation values during the winter months, the winter of 2004/05 barely registered any precipitation in southern Portugal and Spain (Fig. 4a, Reliquias, and Fig. 4b, Granada). In fact, the precipitation percentage recorded, compared to the normal 1961-90, from mid-December 2004 to mid-February 2005 was below $8 \%$ in both stations.

Figure 5 compares the monthly accumulated precipitation between January 2004 and September 2005 with the long-term climatology (1865-2005) for the Lisbon observatory. The 2004/05 drought was the driest in the last $140 \mathrm{yr}$ at this location. The major drought spanned the period from November 2004 to June 2005; every
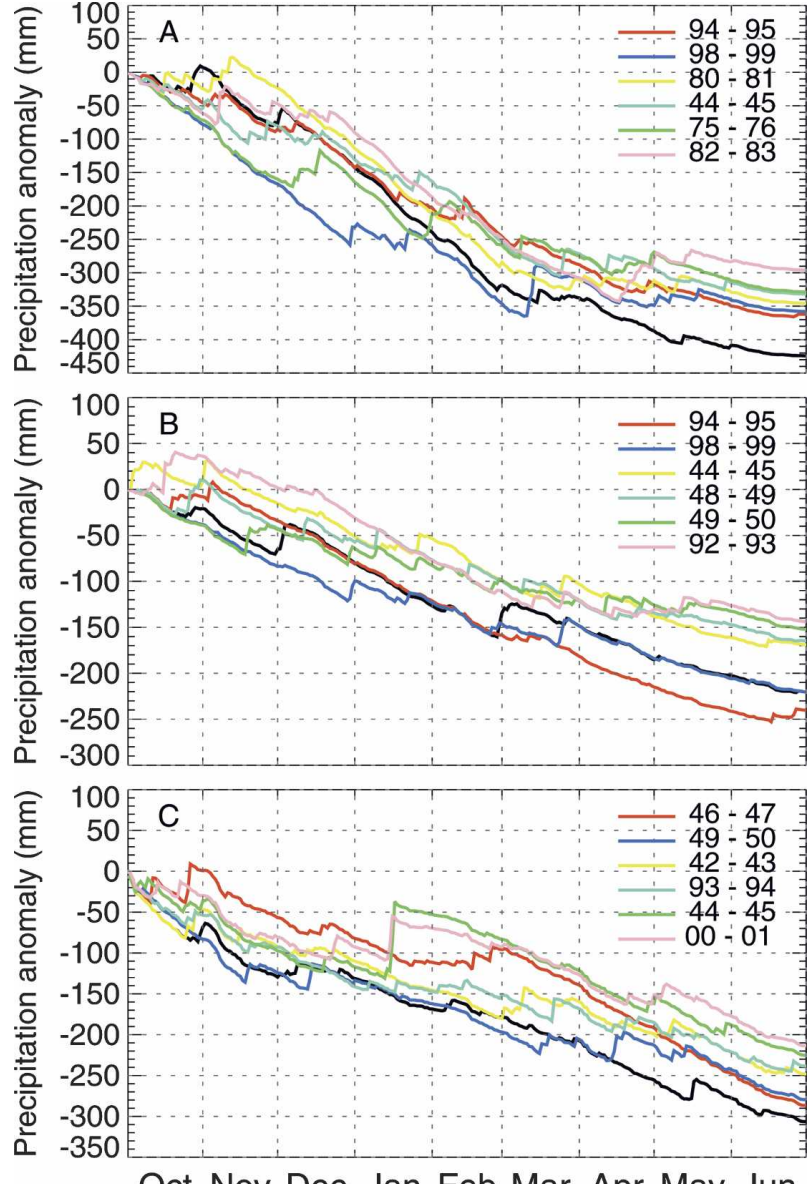

Oct Nov Dec Jan Feb Mar Apr May Jun

FIG. 4. Daily accumulated precipitation anomaly compared to the 1961-90 normal for the stations at (a) Reliquias, (b) Granada, and (c) Barcelona. Black line depicts the precipitation anomaly recorded during the October 2004-June 2005 period. The colored lines display the six greater droughts ever recorded in each station (1941-2005 period) during the corresponding October (year $n-$ 1) to June (year $n$ ) hydrological year.

month within this period presented values below the 30th percentile of the long-term climatology. It is worth noticing that the severe effects of this major drought on the hydrological cycle were enhanced by the previous "minor" drought that occurred between February and June 2004 (Fig. 5), where every month (except March) recorded precipitation values below the 30th percentile. This fact is particularly relevant for water resources management, as it highlights the water-stressed level already present at the beginning of the 2004/05 hydrological year. Naturally, despite the observed wet October 2004, levels of soil moisture decreased continuously since the beginning of 2004, reaching extremely low values at the end of spring 2005 with negative impacts on vegetation growth.

We have computed monthly precipitation percent- 


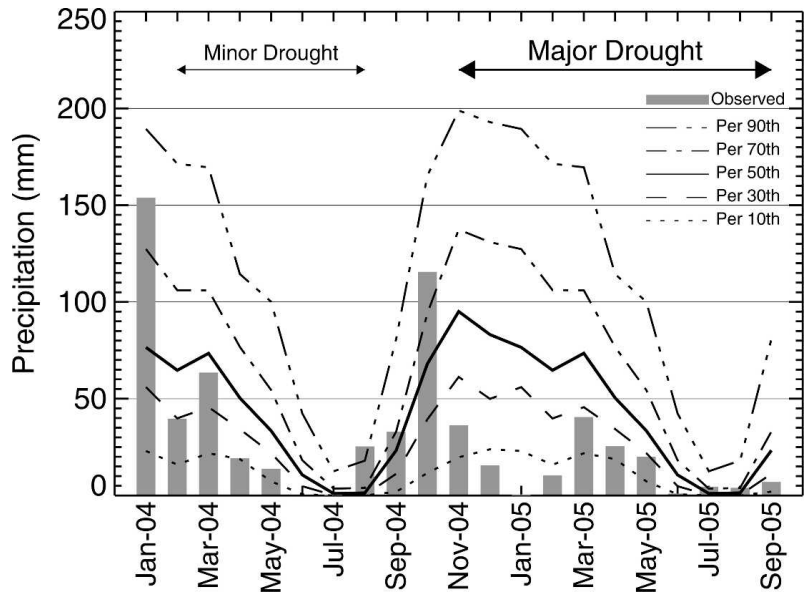

FIG. 5. Monthly accumulated precipitation at Lisbon (gray bars) compared to different percentiles (described in the legend at the top-right corner of the figure) computed for the 1865-2005 period.

ages with respect to the corresponding climatological (1961-90) normals (Fig. 6). This was done using the monthly dataset maintained by the GPCC and restricted to areas with significant climatological monthly rainfall amounts $(>20 \mathrm{~mm})$ in order to avoid misleading results over southern Europe and northern African regions. During the core winter period (NovemberMarch), most of the Spanish and Portuguese territory presented accumulated precipitation values lower than $50 \%$ of the normal period 1961-90. The exceptions were relatively small, like the Mediterranean and northern coastal areas, which recorded precipitation values slightly above the average values in December and February (Fig. 6).

However, the dry conditions continued to prevail until June throughout the Iberian Peninsula, particularly for the southern half (Fig. 6). Some precipitation was recorded in March and May in western Iberia but with a minor effect on the accumulated precipitation anomaly (e.g., Fig. 4a). Naturally, the lack of spring precipitation was crucial to understand the widespread amplitude of this drought and its socioeconomic impacts. In fact, some of the former historical droughts (Fig. 4) presented a greater recovery during spring months, which is not present in the 2004/05 episode. This was particularly problematic for the eastern half of Iberia, where the spring precipitation is usually higher than that recorded during winter.

\section{b. Europe and northern Africa}

Taking a broader look at the European monthly precipitation for the November 2004-June 2005 period, it is evident that this episode affected the precipitation regime over an extensive area that extended over western Europe and northern Africa (Fig. 6). These widespread and persistent precipitation anomalies can be associated with corresponding large-scale anomalies of the atmospheric circulation fields of 1000-hPa geopotential height (Fig. 6) and 500-hPa geopotental height (Fig. 7) over the NAE sector.

From November 2004 to February 2005, the vast majority of western Europe and northwestern Africa were under the influence of similar dry conditions that affected Iberia (Fig. 6). In particular, parts of southern United Kingdom and France recorded abnormally low levels of accumulated precipitation that led to drought conditions. In contrast, the eastern (and parts of the central and western) Mediterranean basin recorded high precipitation amounts. As expected, the $1000-\mathrm{hPa}$ geopotential height signature for each month between November 2004 and February 2005 reveals large positive anomalies (significant at $p<0.05$ for February) over the North Atlantic, with maximum amplitude located between Iceland, the United Kingdom, and Azores. Upper-level pressure anomalies (Fig. 7) confirm the overall structure derived at surface level. It must be emphasized that the anomalies show a barotropic structure during the period November 2004 to February 2005, while for the other months, baroclinicity seems to prevail in the anomaly fields.

As a consequence of the high NW-SE gradient of geopotential height, both at the surface and at upper levels, during the December-February period, western Europe was under the influence of strong cold-air advection from northern latitudes. This is particularly clear for February 2005, displaying 850-hPa temperature anomalies below $-2^{\circ} \mathrm{C}$ all over western Europe (Fig. 7). These low temperature values are associated with arctic air outbreaks over Iberia (see, e.g., Madrid, Fig. 8) and northern Africa, being associated with intense episodes of snow in northern and central Spain. Similar patterns were obtained for considerably different settings, such as Granada (southern Iberia) and Barcelona (northern Mediterranean coast).

The dry pattern persisted over much of Europe during the following months, with the exception of April (Fig. 6) when above-average precipitation values were recorded for almost the entire continent (except for Scandinavia and as far as Greece). During April and May the North African coast close to Iberia also recorded some of the lowest precipitation amounts during this drought ( $<25 \%$ of the normal). The $500-\mathrm{hPa}$ geopotential height field during these 3 months (Fig. 8) shows consistent positive anomalies (at $p<0.05$ in May and June) located exactly over the western North African coast, immediately under Iberia (April), that dis- 

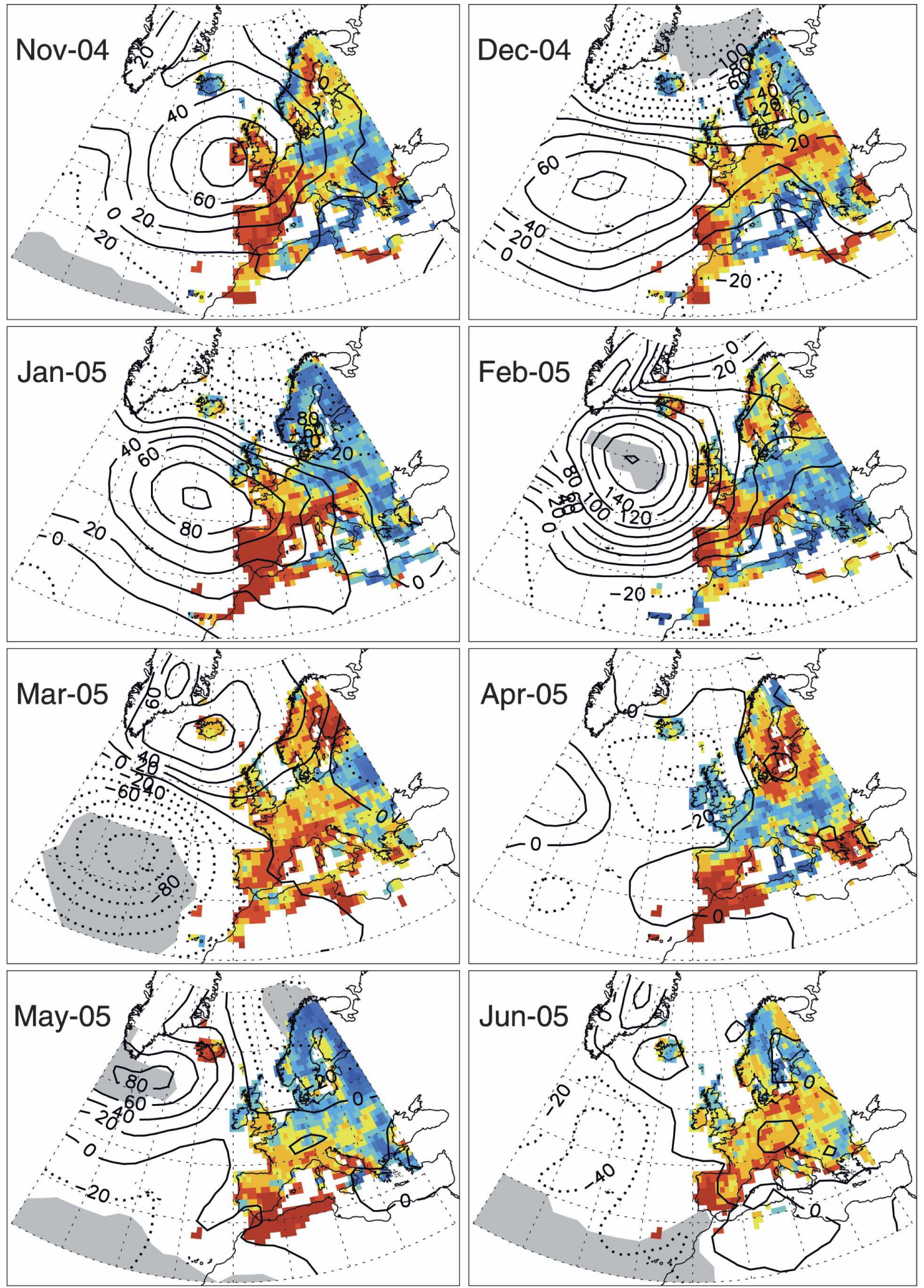

\section{$25 \quad 50 \quad 75 \quad 100 \quad 125 \quad 150 \quad 175 \quad 200 \quad 250$}

FIG. 6. Monthly anomalies of 1000-hPa geopotential height (gpm; lines) and precipitation percentage from the normal 1961-90 (colored shading) between November 2004 and June 2005. Data obtained from ECMWF and GPCC, respectively. The gray shading highlights those regions where the $1000-\mathrm{hPa}$ geopotential height anomalies are significantly different from the climatology (derived between 1961 and 1990) at the 5\% level. 

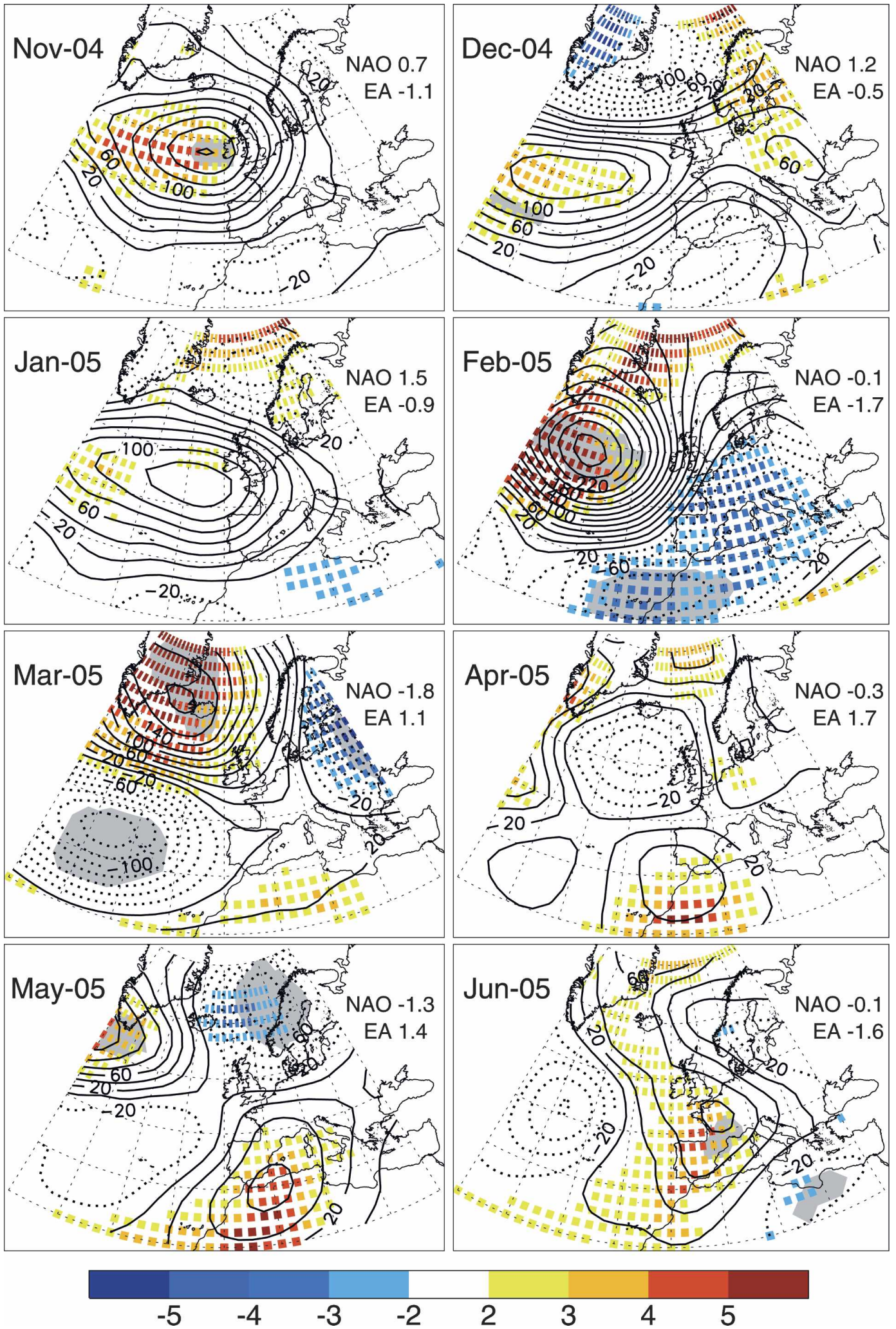

FIG. 7. Monthly anomalies of 500-hPa geopotential height (gpm; lines) and 850-hPa temperature anomaly field ( ${ }^{\circ} \mathrm{C}$; colored squares) between November 2004 and June 2005. The gray shading highlights those regions where the 500-hPa geopotential height anomalies are significantly different from the climatology at the $5 \%$ level. All data from ECMWF (climatology derived between 1961 and 1990). The corresponding NAO and EA monthly indexes (CPC) are displayed in the top-right corner of each panel. 


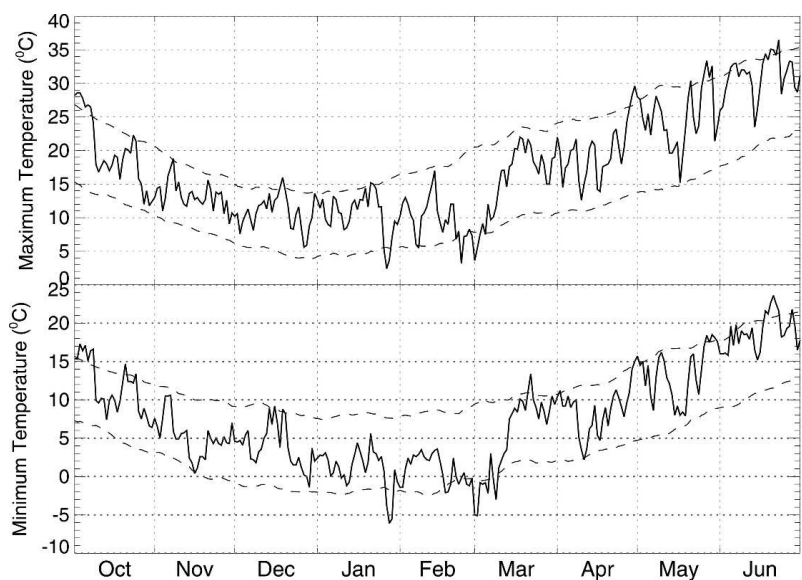

FIG. 8. (top) Daily maximum and (bottom) minimum temperatures recorded at the Madrid station from October 2004 to June 2005. Dashed lines represent the 95th and 5th percentiles of the respective daily maximum and minimum temperatures during the 1951-2000 period; both percentile lines have been smoothed with a 9-day moving average.

placed northward to reach western Europe (June). In fact, these anomalies resemble the usual positive phase of EA, particularly so for April, explaining the high precipitation totals obtained over the United Kingdom and France. Despite the relatively minor amplitude of positive 1000-hPa geopotential height anomalies (Fig. 6), these remained over southwestern Europe inducing low precipitation totals over the western North African coastal and western Europe regions. Furthermore, hot and dry air from the south was advected into northern Africa and southwestern Europe (Fig. 7), displaying large positive temperature anomalies at $850 \mathrm{hPa}$ (above $4^{\circ} \mathrm{C}$ under the center of the high). These above-normal temperatures also had an impact on surface temperatures, particularly increasing the minimum temperatures above the 95th percentile distribution over Iberia (Fig. 8).

\section{Synoptic circulation anomalies over Iberia based on weather types}

It was shown before (Fig. 5) that the 2004/05 drought corresponded to the most extreme event registered in Lisbon over the last $140 \mathrm{yr}$. Here, this extreme event will be assessed for Lisbon at the daily scale, between October 2004 and June 2005, based on the impact of different WTs (Fig. 9).

The WTs contributing to the highest fraction of winter (DJF) precipitation over Iberia are the $\mathrm{C}$ and those with a predominant directional flow from the Atlantic (hereafter $\mathrm{W}, \mathrm{SW}$, or $\mathrm{NW}$ ). This is particularly visible

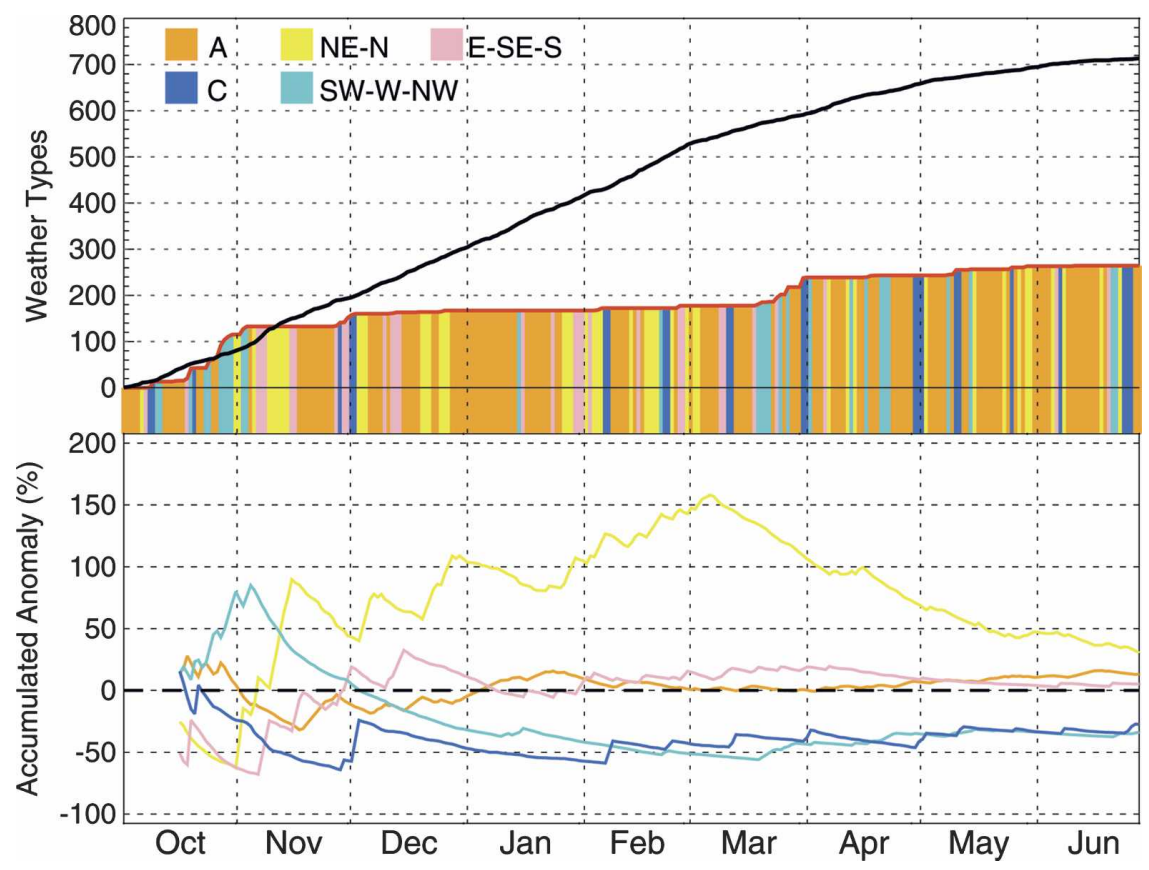

FIG. 9. (top) Mean daily accumulated precipitation for Lisbon for the normal 1961-90 period (solid black line). The red solid line depicts the daily accumulated precipitation for the October 2004-June 2005 period. The colored bands display the daily weather types computed. (bottom) Daily accumulated frequency anomaly (\%) for the weather types; each colored line corresponds to the same weather type displayed in the above graphic. 
TABLE 1. (Above) Combined percentage of accumulated precipitation for the grouped WTs in the fall [September-November (SON)], winter (DJF), and spring [March-May (MAM)] seasons during the 1958-97 period. (Below) Relative frequency of each group (\%).

\begin{tabular}{lrcrrr}
\hline & C & SW-W-NW & \multicolumn{1}{c}{ A } & N-NE & S-SE-E \\
\hline Winter & 22.2 & 59.5 & 6.6 & 3.0 & 8.7 \\
& 7.8 & 28.1 & 40.2 & 8.6 & 15.3 \\
Fall & 28.8 & 51.5 & 5.6 & 2.9 & 11.2 \\
& 8.4 & 24.5 & 36.9 & 16.5 & 13.8 \\
Spring & 31.8 & 48.0 & 4.8 & 8.4 & 7.0 \\
& 10.9 & 23.5 & 32.7 & 21.4 & 11.6 \\
\hline
\end{tabular}

for Lisbon, where the C WT (occurring on average for about $7.8 \%$ of DJF days) and a combination of the SW-W-NW types (with an average frequency of $28.1 \%$ ), contribute to $22.2 \%$ and $59.5 \%$, respectively, of the total accumulated precipitation (Table 1). The remaining WTs are much drier, particularly the A type and those dominated by an easterly or southerly flow component. Therefore, during the winter season, WTs can be split into "wet" (C, W, NW, and SW) and "dry" (A, N, NE, S, SE, and E). This division is also applicable to the fall and spring seasons (Table 1).

The combined analysis of wet/dry WT frequency [applied previously elsewhere, e.g., Fowler and Kilsby (2002) for the United Kingdom] and the daily accumulated precipitation for Lisbon, during the October 2004-June 2005 period (Fig. 9), shows a number of interesting features, namely:

1) In October, the accumulated precipitation for Lisbon (red curve) was slightly above the average (black curve). This fact is explained by the abovenormal occurrence of wet WTs (SW-W-NW) during the second fortnight of this month.

2) During November, the anomaly of the accumulated frequency for the dry NE-N WTs increased (yellow curve) to roughly $100 \%$ in mid-November, while the corresponding frequency of the wet SW-W-NW WTs dropped dramatically (light blue curve). Only at the end of November was some marginal precipitation recorded, but the bulk of accumulated precipitation was already below the normal values.

3) From December 2004 until mid-March 2005, the curve for the accumulated precipitation (red line) shows an impressive plateau. During this period the accumulated frequency for both wet WT groups dropped to $55 \%$ of the normal value (by the beginning of March they had been recorded 7.5 days versus an average of 13.25 days for the C WT and 20 days versus an average of 41 days for the combined SW-W-NW group, $56 \%$ and $49 \%$, respectively). In contrast, the contribution of the dry NE-N types increased, reaching a record of $150 \%$ above the normal by the beginning of March (38.5 days compared to the mean value of 15.5 days). Again, at the end of March some precipitation can be seen over western Iberia (Fig. 6) clearly associated with the appearance of wet WTs (Fig. 9).

4) Finally, another precipitation plateau can be observed between April and June, a period that was again dominated by the higher-than-usual occurrence of various dry WTs.

\section{The role of transient low pressure systems (storm tracks)}

The complete trajectories of every cyclone, with a minimum life span of 2 days, detected during the extended winter season (October 2004-March 2005) in the NAE sector is depicted in Fig. 10. It is important to keep in mind that this type of algorithm identifies and follows cyclone centers. Therefore, their associated impact on precipitation extends to the south of each path, accompanying the main fronts associated with the synoptic systems tracked by the algorithm.

The most interesting feature shown in Fig. 10 regards the impressive displacement of cyclone trajectories in the North Atlantic sector to latitudes above $50^{\circ} \mathrm{N}$ from November 2004 to February 2005. This departure from the most usual paths displayed by the low pressure systems in winter (Trigo 2006) is compatible with the large positive anomalies found for $1000-\mathrm{hPa}$ geopotential height charts during these months (Fig. 6). Moreover, there is a complete absence of cyclones crossing the Iberian Peninsula and the western European sector during November 2004 and January 2005, a result that explains the large negative precipitation anomalies recorded for this area (Fig. 6). In March, the strong negative 1000-hPa geopotential height anomalies observed around the Azores archipelago is associated with a large number of cyclones that developed in this area. While a few transient systems passed over lower latitudes (e.g., Morocco) almost none crossed Iberia and the western European sector, which was under the influence of the high pressure system centered over Iceland (Fig. 6). Unlike the Spanish mainland, the important tourist archipelago of the Canary Islands registered above-normal precipitation values at the end of the winter season, particularly in February and March. It is worth noting that the eastern, and parts of the central, Mediterranean basin were affected by numerous cyclones that developed over this area from November 2004 to February 2005, a fact that explains the high precipitation records observed over this sector (Fig. 6). 

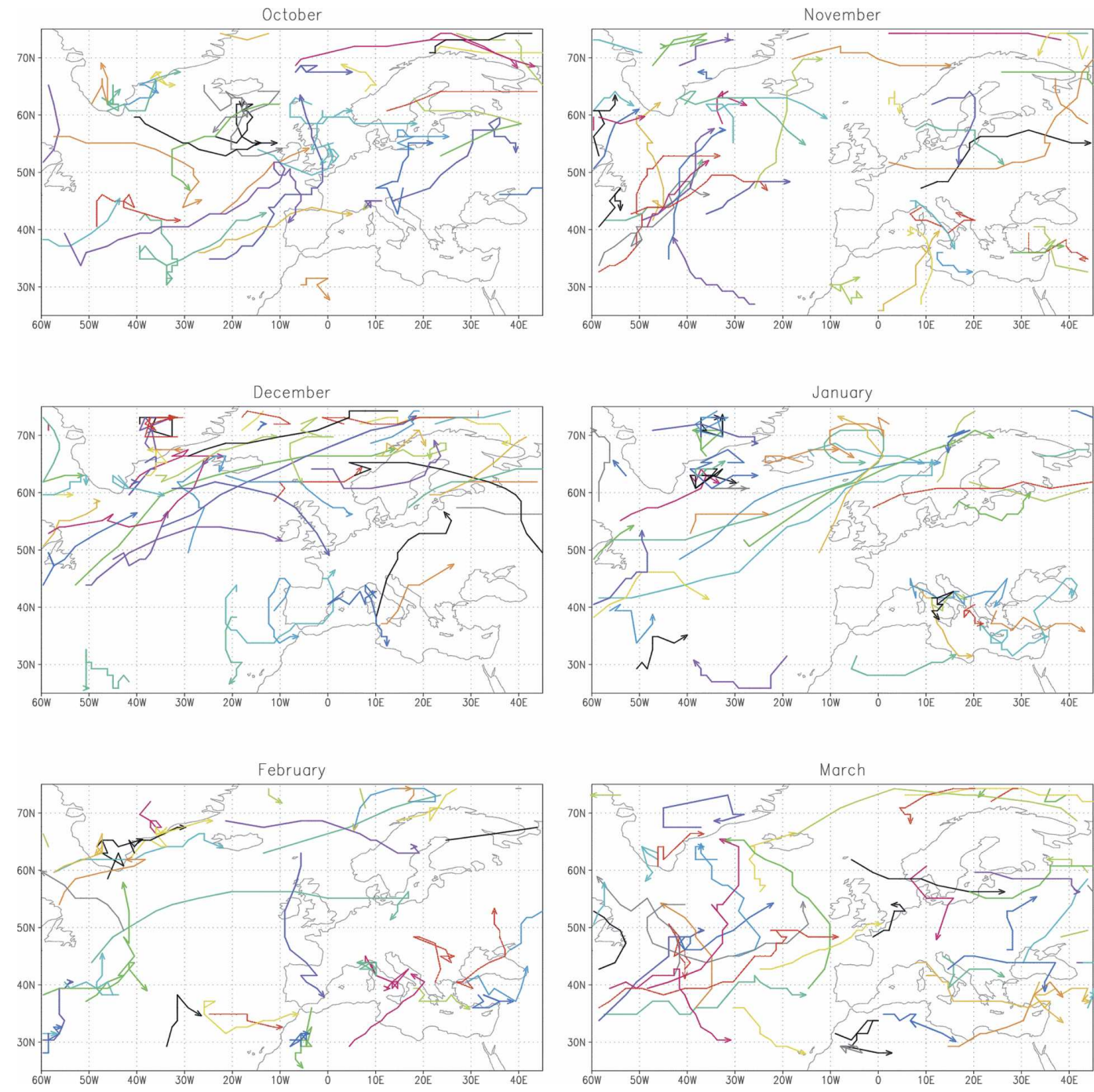

FIG. 10. Path of individual cyclones detected by applying the storm-track methodology from October 2004 to March 2005. Only cyclones lasting at least $48 \mathrm{~h}$ are depicted.

\section{Blocking analysis}

In the previous sections we have characterized the atmospheric circulation associated with the 2004/05 drought in Iberia, at the monthly (section 3 ) and daily (section 4) scales. While indexes associated with wellestablished patterns (such as NAO and EA) are useful to evaluate the average monthly circulation, they often merge several distinct patterns at the submonthly (weekly) scale. Part of this submonthly analysis was therefore presented by showing the complete path of storm tracks, lasting at least 2 days (section 5). However, this approach covers only transient systems and not relatively stable anticylonic patterns. One of the most important large-scale features modulating surface climate in the middle and higher latitudes are blocking events, that is, large anticylonic patterns displaced northward of their usual latitude and lasting between 5 and 25 days (Trigo et al. 2004a; Barriopedro et al. 2006). Here, we have evaluated the location and duration of blocking events throughout the October 2004 to June 2005 period, particularly focused over the Atlantic sector $\left(90^{\circ} \mathrm{W}\right.$ to $0^{\circ}$ longitude), where the influence of blocking events on the western European climate is higher (Trigo et al. 2004a).

The blocking activity from October to December within the Atlantic sector was similar to the corresponding average obtained for the 1958-2005 period (not shown). However, the frequency of blocking events from January to March (JFM) was exceptional, particularly between $40^{\circ}$ and $20^{\circ} \mathrm{W}$, where it surpassed the 95th percentile (Fig. 11a). This high level of block- 

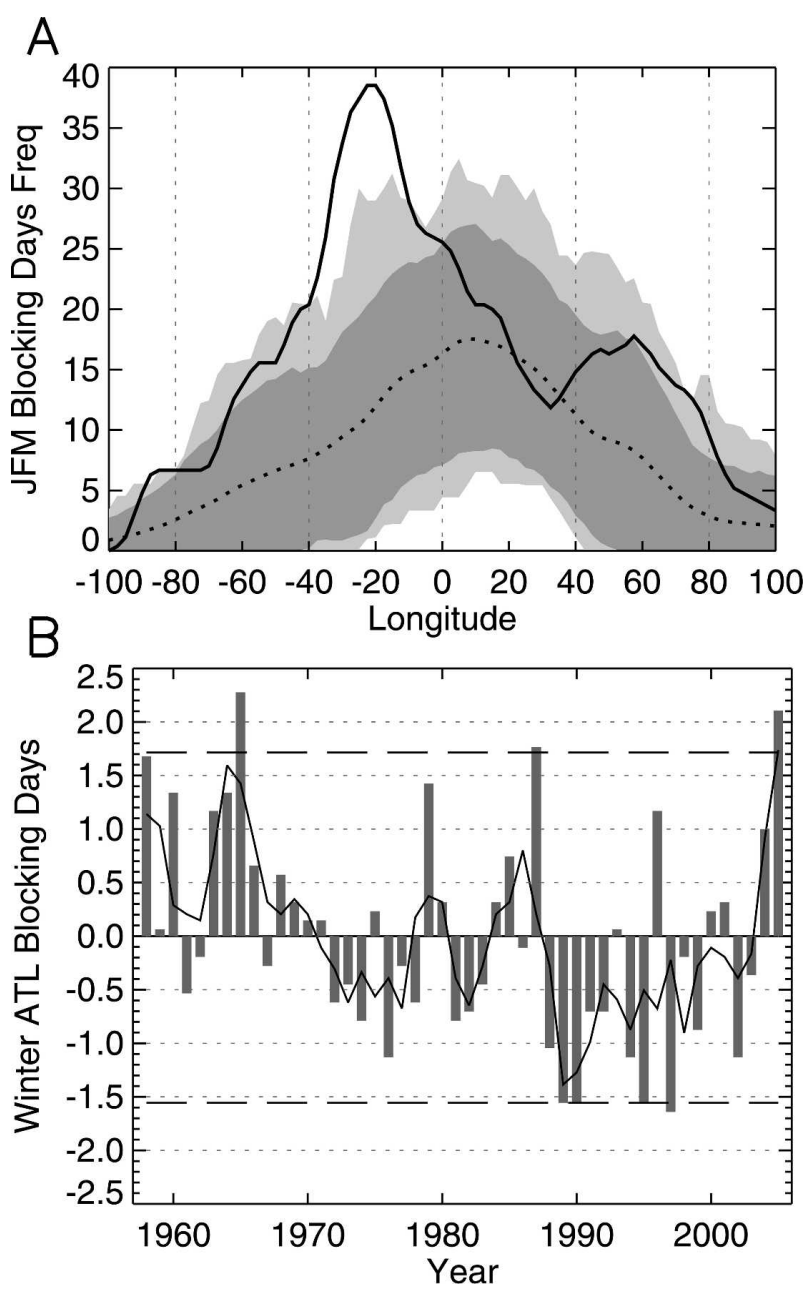

FIG. 11. (a) Longitudinal distribution for the frequency of blocked longitudes in winter (JFM) 2005 (thick solid line) and the averaged distribution for the 1958-2005 period (dashed line). The dark gray shading denotes the 1.0-sigma level deviation from the climatological mean, and the light gray shading depicts the range between the 10th and 90th percentile levels; (b) time series of the standardized anomalies for the number of winter blocking days over the Atlantic sector $\left(90^{\circ} \mathrm{W}-0^{\circ}\right)$ for the $1958-2005$ period. Dashed lines indicate the 5th and 95th percentile levels. The solid line represents the filtered series with a 3 -yr running average.

ing activity over the Atlantic sector can be observed through the time series of standardized anomalies for the number of winter blocking days (1958-2005), being only slightly surpassed by the winter of 1965 (Fig. 11b). Moreover, the blocking activity was remarkable in March, which showed a record-breaking number of blocking days since 1958 (not shown). In fact, the blocking activity in winter was characterized by three persistent and quasi-consecutive blocking events. The first one spanned the second half of January to the beginning of February, centered over the eastern Atlantic Ocean basin. From mid-February to mid-March the At-

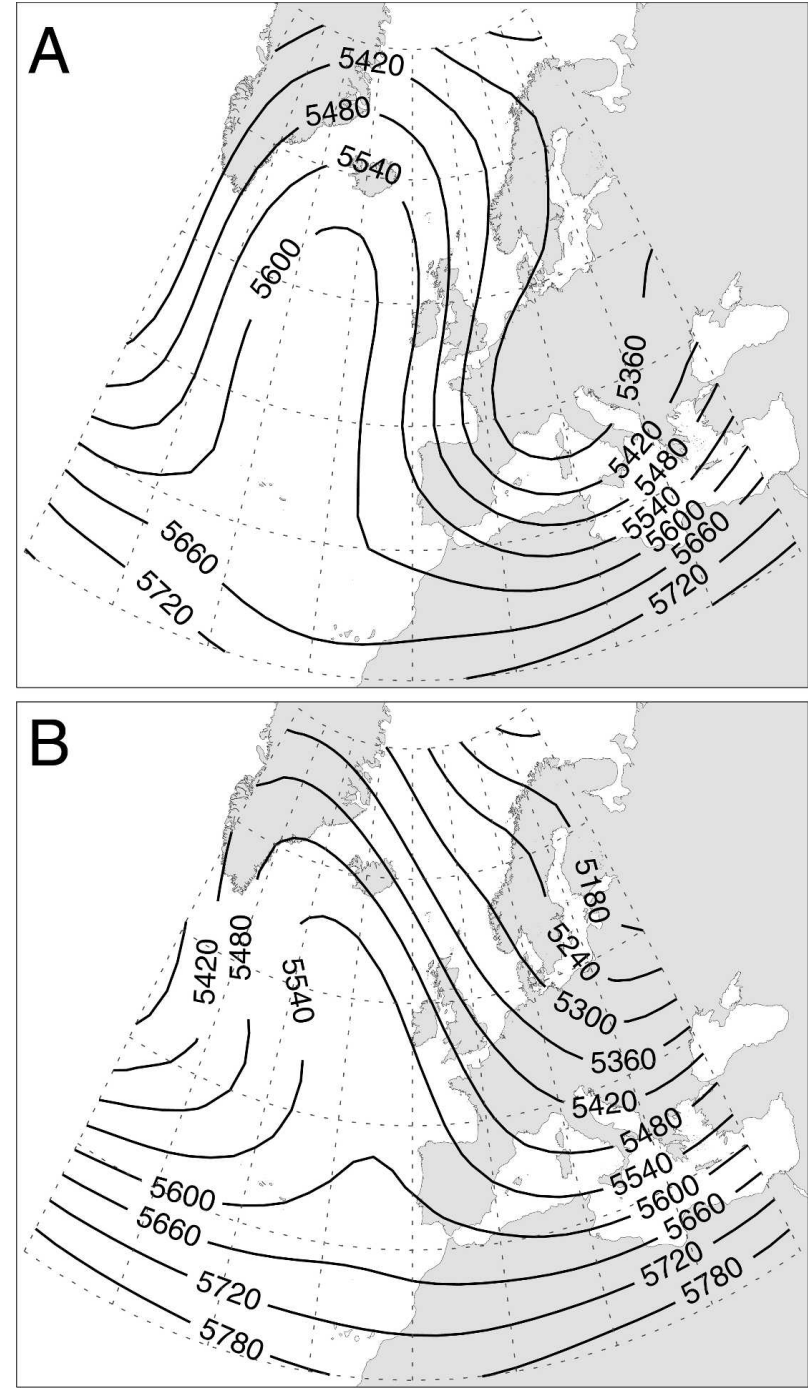

FIG. 12. Composite of the daily 500-hPa geopotential height field for (a) the second fortnight of February 2005 and (b) the first fortnight of March 2005.

lantic sector was consecutively blocked by two persistent episodes, roughly confined to the second fortnight of February (Fig. 12a) and the first fortnight of March (Fig. 12b), both revealing a predominant omega block configuration pattern (Barriopedro et al. 2006) west of Europe.

The enhanced meridional flow component associated with these blocking events explains the preponderance of the northern component WTs during the winter season until mid-March, as well as the scarce precipitation and cold-air advection from northern latitudes in February over western Europe (Fig. 12a). Previous studies have shown that anomalous high-latitude blocking episodes induce below-normal temperatures in the lower troposphere over central and northwestern Europe, as 
a result of cold advection by the anomalously meridional mean flow. Negative temperature anomalies are usually recorded at the surface, since the anticyclonic conditions prevailing also produce an enhanced outgoing flux of longwave radiation at night due to clearer skies (Trigo et al. 2004a). The intensification of the meridional component of the midtroposphere circulation and the NE-SW tilt of the block axis favored coldair intrusions over Europe and northern Africa (Fig. 7), contributing to the occurrence of several snow events in February in the Iberian Peninsula. The persistent blocking event during the first fortnight of March caused the displacement of the usual path of cyclones north of Iberia (Figs. 12b and 10). In contrast, the second half of March was dominated by the absence of blocking activity and thus a more westerly flow, in agreement with the slight increase of precipitation recorded in some regions of western Iberia.

After the month of March the blocking activity decreased through spring (with the exception of May). Thus, in summary, although only three blocking events were detected over the Atlantic sector, more than 50\% of the winter days were blocked, showing the winter 2005 as the most active one since 1965 .

\section{Conclusions and discussion}

The 2004/05 hydrological year was characterized by an intense drought throughout western Europe, reaching record levels over the Iberian Peninsula. In particular, the southern half of Iberia received less than $45 \%$ of the usual precipitation between October 2004 and June 2005. The hydrological year from October 2004 to September 2005 was the driest on record at several locations throughout Iberia, in particular Lisbon (since 1865) and Madrid (since 1859). This outstanding event had major socioeconomic impacts in both Iberian countries (Portugal and Spain), particularly concerning hydroelectricity and cereals production, which decreased to $40 \%$ and $60 \%$ of the average, respectively.

An Eulerian approach by means of a weather-type classification shows that the major rainfall contributors for Iberia in winter display significant low frequencies throughout the study period, while dry WTs prevailed. While the WT technique detects low pressure systems when they are crossing Iberia (C), or are about to cross (W, NW, SW), it does not provide information on the full path of these transient low pressure systems. An explicit Lagrangean storm-track algorithm over a wide northern Atlantic sector confirms the generalized absence, over Iberia, of storm tracks throughout the winter months of the 2004/05 hydrological year, with the important exception of October 2004. The record- breaking blocking frequency during most of the winter explains these anomalous circulation patterns.

Work published in the last decade has shown that several teleconnections may account for a significant part of winter precipitation variability in Iberia. Among them, the NAO plays the most relevant role (Trigo et al. 2004b, 2005), while the EA pattern also accounts for a significant percentage of precipitation variability in Iberia (Sáenz et al. 2001). Finally, other authors show that La Niña events may precede drought episodes over Iberia (e.g., Vicente-Serrano 2005; Pozo-Vázquez et al. 2005). Consequently, we investigated the role of these teleconnections in the 2004/05 Iberian drought.

The 2004/05 hydrological year was characterized by a weak El Niño event, confirming the negligible impact of SST anomalies over the Pacific Ocean on this drought episode. However, the scarce precipitation records obtained in the Iberian Peninsula between December 2004 and January 2005 match with the positive NAO index displayed (1.2 and 1.5, respectively). In February, the NAO index $(-0.1)$ can hardly provide a clear explanation to the scarce precipitation registered during this month. In this case, the negative EA index $(-1.7)$, which is related to the anomalous high pressure west of the United Kingdom, provides the better explanation for low precipitation values observed in this month.

Interestingly, in March neither the NAO (-1.8) nor the EA (1.1) are capable of explaining the large negative precipitation anomalies displayed over most of the European continent. The precipitation anomaly pattern can be regarded as a particularly awkward one, since strong negative NAO index values are usually associated with above-normal precipitation over Iberia and the western Mediterranean (Hurrell 1995; Trigo et al. 2004b). This departure from the usual NAO precipitation association pattern is due to the record-breaking blocking episode registered in the first fortnight of March 2005. Blocking episodes are typically associated with significant meridional shifts in the location of storm tracks characterized by a lack of cyclones over northern Europe and a southward displacement of transient eddy activity toward the Iberian Peninsula (Trigo et al. 2004a). However, the March 2005 blocking showed some peculiarities. The anomalous blocking activity in March associated with negative NAO values is in agreement with the reported increase in blocked days and blocking durations over the Atlantic sector during the negative phases of the NAO (Shabbar et al. 2001; Barriopedro et al. 2006). In addition, Barriopedro et al. (2006) reported that the blocking response to NAO also reveals some asymmetry in the location of blocking episodes. Thus, blocking events occurring 


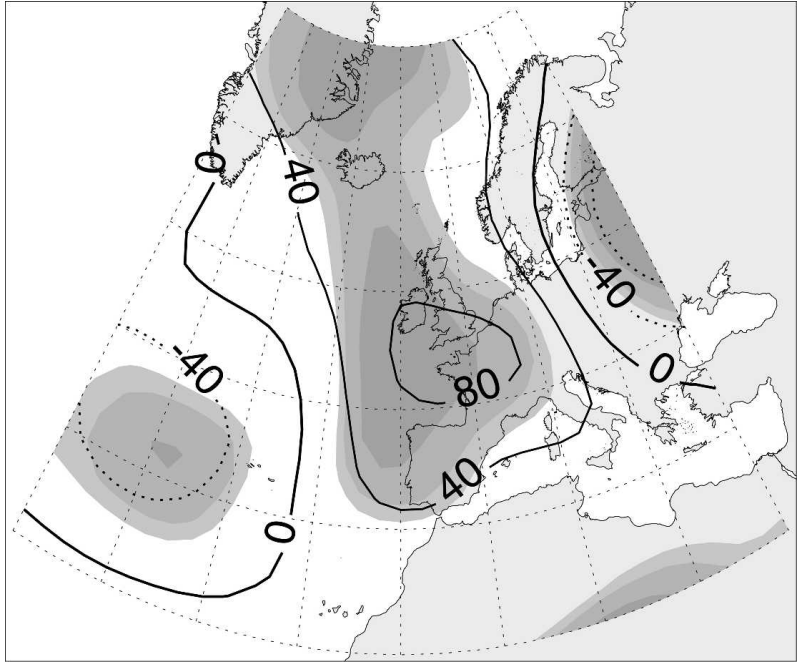

FIG. 13. Difference of composites for blocking days (at 500-hPa height) over the Atlantic sector between March 2005 and those months of March with negative NAO index registered in the 1958-2005 period. Shaded areas indicate significant differences at $90 \%, 95 \%$, and $99 \%$ levels after a two-tailed $t$ test.

during negative phases of the NAO are relatively more (less) frequent along a band stretching between Greenland and Iceland (United Kingdom and northern Europe) than those associated with the positive NAO phase. This northwestern displacement of blocking centers for the negative phases of the NAO is on the order of $5^{\circ}$ in latitude and $30^{\circ}$ in longitude, favoring the appearance of cyclones crossing over Iberia and the western Mediterranean (Barriopedro et al. 2006).

Figure 13 depicts the difference at $500-\mathrm{hPa}$ geopotential height between the blocked days of March 2005 and those occurring during the negative NAO phase (in March) during the 1958-2005 period. It can be seen how the enhanced cyclone trajectory across the southern half of Iberia, which is typically observed during high blocking situations, was dramatically cut off by an anomalous southeastern elongation of the blocking pattern. The southward extension of the blocking action toward lower-than-usual latitudes and the preference for blocked longitudes around $20^{\circ} \mathrm{W}$ interrupted the cyclone tracks across the Iberian Peninsula and prolonged the drought through the first half of the month. Thus, although the number of cyclones in lower latitudes increased notably in March, in agreement with the negative NAO index, its activity was confined to two isolated centers of action located over Azores and the eastern Mediterranean (Fig. 10). The southern branch of transient activity expanding between both centers and through Iberia was almost suppressed and anomalously displaced southward toward the Morocco coastline, leading to above-normal precipitation over the Canary Islands and northern Africa. In addition, the anomalous intensity and extension of the block is able to explain the impressive extension of low rainfall records toward the western and central Europe, even reaching Scandinavia, which is a typical feature of Atlantic blocks (Trigo et al. 2004a).

Thus, we can conclude that the 2004/05 Iberia drought is attributable to three main factors that occurred successively: a NAO positive pattern from November to January, a positive EA pattern in February, and a record-breaking blocking episode, which extended from mid-February to mid-March. The atmospheric circulation analysis at the submonthly scale in March has highlighted a certain limitation of the teleconnection indexes to explain precipitation extremes. The results obtained within this work show the NAO and EA indexes, two of the most prominent North Atlantic teleconnection patterns modulating climate in the Iberian Peninsula, incapable to detect the low precipitation totals in March.

In fact, the explanation for this anomalous event was obtained through the detailed analysis of the blocking pattern at the submonthly scale. The subweekly objective methods used in this work, storm tracks and weather-types approach, are also key techniques to characterize the atmospheric circulation during extreme events. This has been shown previously for the analysis of the 2003 heat wave in Europe, which also presented particularly dry conditions (Fink et al. 2004), and also describes the circulation anomalies inducing significant precipitation trends (Paredes et al. 2006)

Even when a systematic analysis of the Iberian droughts and their associated atmospheric circulation is not available yet, it is known that they occur under a wide variety of distinct synoptic patterns (VicenteSerrano 2006a; Haylock and Goodess 2004). The use of objective tools as those used in this paper, applied in the appropriate time scale, a work currently in progress by the authors, will improve significantly our current knowledge of droughts and the underlying dynamics and provide a framework for the analysis of extreme droughts that is currently lacking.

Acknowledgments. This work was partially supported by the Spanish Ministry of Science through Grant HP 2004-0039. We also thank the Instituto Nacional de Meteorología (INM) for providing the precipitation data for the Spanish stations. R. M. Trigo was supported by Projects VAST (Variability of Atlantic Storms and their impact on land climate), Contract POCTI/CTA/ 46573/2002, and CLIMAAT (Climate and Meteorology of the Atlantic Archipelagos), Interreg IIIb A3/2.3, 
both cofinanced by the EU under program FEDER. Three anonymous reviewers also helped to improve this manuscript.

\section{REFERENCES}

Barriopedro, D., R. García-Herrera, A. R. Lupo, and E. Hernández, 2006: A climatology of Northern Hemisphere blocking. J. Climate, 19, 1042-1063.

Briffa, K. R., P. D. Jones, and M. Hulme, 1994: Summer moisture variability across Europe, 1892-1991: An analysis based on the Palmer drought severity index. Int. J. Climatol., 14, 475506.

Dai, A. G., K. E. Trenberth, and T. R. Karl, 1998: Global variations in droughts and wet spells: 1900-1995. Geophys. Res. Lett., 25, 3367-3370.

, and T. Qian, 2004: A global dataset of Palmer Drought Severity Index for 1870-2002: Relationship with soil moisture and effects of surface warming. J. Hydrometeor., 5, 11171130.

Delitala, A. M. S., D. Cesari, P. A. Chessa, and M. N. Ward, 2000: Precipitation over Sardinia (Italy) during the 1946-1993 rainy season and associated large-scales climate variations. Int. J. Climatol., 20, 519-541.

Esteban-Parra, M. J., F. C. Rodrigo, and Y. Castro-Díez, 1998: Spatial and temporal patterns of precipitation in Spain for the period 1880-1992. Int. J. Climatol., 18, 1557-1574.

Fink, A. H., T. Brücher, A. Krüger, G. C. Leckebusch, J. G. Pinto, and U. Ulbrich, 2004: The 2003 European summer heat waves and drought-Synoptic diagnosis and impacts. Weather, 59, 209-216.

Fowler, H. J., and C. G. Kilsby, 2002: Precipitation and the North Atlantic Oscillation: A study of climatic variability in northern England. Int. J. Climatol., 22, 843-866.

Goodess, C. M., and P. D. Jones, 2002: Links between circulation and changes in the characteristics of Iberian rainfall. Int. J. Climatol., 22, 1593-1615.

Haylock, M. R., and C. M. Goodess, 2004: Interannual variability of European extreme winter rainfall and links with mean large-scale circulation. Int. J. Climatol., 24, 759-776.

Hurrell, J. W., 1995: Decadal trends in the North Atlantic Oscillation: Regional temperatures and precipitation. Science, 269, 676-679.

INAG, 2006: Relatório de Balanço da Seca de 2005 (report on the 2005 drought). Comissão para a Seca 2005. Instituto da Água, 104 pp. [Available online at http://www.inag.pt/inag2004/ port/divulga/actualidades/seca/relatorioBalanco.pdf.]

Lana, X., C. Serra, and A. Burgueño, 2001: Patterns of monthly rainfall shortage and excess in terms of the standardized precipitation index for Catalonia (NE Spain). Int. J. Climatol., 21, 1669-1691.

Lloyd-Hughes, B., and M. A. Saunders, 2002a: A drought climatology for Europe. Int. J. Climatol., 22, 1571-1592.

$\longrightarrow$, and — 2002b: Seasonal prediction of European spring precipitation from El Niño-Southern Oscillation and local sea-surface temperatures. Int. J. Climatol., 22, 1-14.

Maheras, P., E. Xoplaki, and H. Kutiel, 1999: Wet and dry monthly anomalies across the Mediterranean basin, and their relationship with circulation, 1860-1990. Theor. Appl. Climatol., 64, 189-199.

Mariotti, A., M. Zeng, and K. M. Lau, 2002: Euro-Mediterranean rainfall and ENSO-A seasonally varying relationship. Geophys. Res. Lett., 29, 1621, doi:10.1029/2001GL014248.

Martín-Vide, J., and L. Gómez, 1999: Regionalisation of peninsular Spain based on the length of dry spells. Int. J. Climatol., 19, 537-555.

MMA, 2006: Informe balance del año hidrológico 2004-2005 (report on the hydrological year 2004-2005). Programa A.G.U.A., Ministerio de Medio Ambiente, 141 pp. [Available online at http://www.mma.es/portal/secciones/acm/ aguas_continent_zonas_asoc/ons/mapa_informe_ons/ informes_cuenca.htm.]

Paredes, D., R. M. Trigo, R. García-Herrera, and I. F. Trigo, 2006: Understanding precipitation changes in Iberia in early spring: Weather typing and storm-tracking approaches. J. Hydrometeor., 7, 101-113.

Pozo-Vázquez, D., M. J. Esteban-Parra, F. S. Rodrigo, and Y. Castro-Díez, 2001: A study on NAO variability and its possible non-linear influences on European surface temperatures. Climate Dyn., 17, 701-715.

_, S. R. Gámiz-Fortis, J. Tovar-Pescador, M. J. Esteban-Parra, and Y. Castro-Díez, 2005: El Niño-Southern Oscillation events and associated European winter precipitation anomalies. Int. J. Climatol., 25, 17-31.

Qian, B., J. Corte-Real, and H. Xu, 2000: Is the North Atlantic Oscillation the most important atmospheric pattern for precipitation in Europe? J. Geophys. Res., 105, 11 901-11 910.

Rodó, X., E. Baert, and F. A. Comín, 1997: Variations in seasonal rainfall in southern Europe during the present century: Relationships with the North Atlantic Oscillation and the El Niño-Southern Oscillation. Climate Dyn., 13, 275-284.

Rodriguez-Puebla, C., A. H. Encinas, S. Nieto, and J. Garmendia, 1998: Spatial and temporal patterns of annual precipitation variability over the Iberian Peninsula. Int. J. Climatol., 18, 299-316.

Rudolf, B., and A. Meyer-Christoffer, 2005: Hydrometeorological conditions during the extremely dry year 2003 in the longterm and European context. Annual Bulletin on the Climate in WMO Region VI-2003, 87-93.

- , and U. Schneider, 2005: Calculation of gridded precipitation data for the global land-surface using in-situ gauge observations. Proc. Second Workshop of the International Precipitation Working Group IPWG, Monterey, CA, EUMETSAT, 231-247.

Sáenz, J., J. Zubillaga, and C. Rodríguez-Puebla, 2001: Interannual variability of winter precipitation in northern Iberian Peninsula. Int. J. Climatol., 21, 1503-1513.

Serrano, A., A. J. Garcia, V. L. Mateos, M. L. Cancillo, and J. Garrido, 1999: Monthly modes of variation of precipitation over the Iberian Peninsula. J. Climate, 12, 2894-2919.

Shabbar, A., J. Huang, and K. Higuchi, 2001: The relationship between the wintertime North Atlantic Oscillation and blocking episodes in the North Atlantic. Int. J. Climatol., 21, 355-369.

Trigo, I. F., 2006: Climatology and interannual variability of storm-tracks in the Euro-Atlantic sector: A comparison between ERA-40 and NCEP/NCAR reanalyses. Climate Dyn., 26, 127-143.

_ T. T. D. Davies, and G. R. Bigg, 1999: Objective climatology of cyclones in the Mediterranean region. J. Climate, 12, 16851696.

— , G. R. Bigg, and T. D. Davies, 2002: Climatology of cyclogenesis mechanisms in the Mediterranean. Mon. Wea. Rev., 130, 549-569. 
Trigo, R. M., and C. C. DaCamara, 2000: Circulation weather types and their impact on the precipitation regime in Portugal. Int. J. Climatol., 20, 1559-1581.

_ - T. J. Osborn, and J. Corte-Real, 2002: The North Atlantic Oscillation influence on Europe: Climate impacts and associated physical mechanisms. Climate Res., 20, 9-17.

— I. F. Trigo, C. C. DaCamara, and T. J. Osborn, 2004a: Climate impact of the European winter blocking episodes from the NCEP/NCAR reanalyses. Climate Dyn., 23, 17-28.

— , D. Pozo-Vázquez, T. J. Osborn, Y. Castro-Díez, S. GámizFortis, and M. J. Esteban-Parra, 2004b: North Atlantic Oscillation influence on precipitation, river flow and water resources in the Iberian Peninsula. Int. J. Climatol., 24, 925-944.
—, J. L. Zêzere, M. L. Rodrigues, and I. F. Trigo, 2005: The influence of the North Atlantic Oscillation on rainfall triggering of landslides near Lisbon. Nat. Hazards, 36, 331-354.

Uppala, S. M., and Coauthors, 2005: The ERA-40 reanalysis. Quart. J. Roy. Meteor. Soc., 131, 2961-3012.

Vicente-Serrano, S. M., 2005: El Niño and La Niña influence on droughts at different time scales in the Iberian Peninsula. Water Resour. Res., 41, W12415, doi:10.1029/2004WR003908.

_ 2006a: Differences in spatial patterns of drought on different time scales: An analysis of the Iberian Peninsula. Water Resour. Manage., 20, 37-60

_ 2006b: Spatial and temporal analysis of droughts in the Iberian Peninsula (1910-2000). Hydrol. Sci. J., 51, 83-97. 